\title{
The use of karyotyping in the systematics of yeasts
}

\author{
Teun Boekhout ${ }^{1}$, Marianne Renting ${ }^{2}$, W. Alexander Scheffers ${ }^{2} \&$ Ron Bosboom ${ }^{3}$ \\ ${ }^{1}$ CBS Yeast Division, Julianalaan 67, 2628 BC Delft, The Netherlands; ${ }^{2}$ Department of Microbiology and \\ Enzymology, Kluyver Laboratory of Biotechnology, Delft University of Technology, Julianalaan 67, 2628 BC \\ Delft, The Netherlands; ${ }^{3}$ Department of Medical Microbiology, Academic Hospital Leiden, The Netherlands
}

Received 20 November 1992; accepted 1 March 1993

Key words: yeast, taxonomy, karyotyping, Hortaea, Filobasidiella, Malassezia

\begin{abstract}
The use of electrophoretic karyotyping in systematics of yeasts is discussed. New data are provided on the karyotypes of the medically important fungi Hortaea werneckii, Filobasidiella (= Cryptococcus) neoformans, and Malassezia species. Hortaea werneckii has twelve to eighteen bands of chromosomal DNA, ranging in size between 500 and $2300 \mathrm{~kb}$. The karyotypes of Filobasidiella neoformans consist of seven to fourteen bands of chromosomal DNA. The varieties neoformans and bacillispora cannot be separated by their karyotypes, and no obvious correlation was found with serotypes, geography or habitat. All strains of Malassezia pachydermatis studied have similar karyotypes consisting of five bands, whereas in $M$. furfur, four different karyotypes are prevalent. However, each of these karyotypes is stable.
\end{abstract}

\section{Introduction}

The numbers of chromosomes as well as deviations from the basic number provide useful information for systematics and breeding in higher organisms such as plants and animals. Chromosomes are the subject of study in cytogenetics, quantitative cytochemistry and biosystematics. Apparent mosaic character states sometimes are related to polyploid complexes (both euploid and aneuploid series), and mechanisms such as allopolyploidization and apomixis play a role in sympatric and allopatric speciation models. Heteroploidy (i.e., deviations from the basic number of chromosomes) also seems to occur in fungi (Tolmsoff 1983). Ploidy differences have been reported in Saccharomyces cerevisiae, Schizosaccharomyces pombe and Candida albicans. Indirect evidence for the occurrence of differences in ploidy has been reported in the basidiomycetous yeasts Sporobolomyces salmonicolor (van der Walt
\& Pitout 1969) and Itersonilia perplexans (Boekhout \& Jille 1991) by biochemical or fluorometric methods. Analysis of karyotypes is a direct means to provide evidence for the presence of heteroploi$\mathrm{dy}$ in yeasts and fungi.

The physical study of yeast chromosomes has been hampered by their small size. Genetic techniques to analyze linkage groups were applied to several perfect fungi, including some yeasts, e.g., Saccharomyces cerevisiae. However, imperfect yeasts cannot be studied using traditional genetics. Another approach to obtain direct evidence for chromosome numbers is cytochemical staining of mitotic chromosomes with Giemsa, e.g., in Kluyveromyces lactis and Saccharomyces cerevisiae (Galeotti \& Williams 1978), Lipomyces lipofer (Robinow 1961), andSchizosaccharomyces pombe (Fisher et al. 1975). DNA-binding fluorochromes like DAPI, mithramicin and para-rosaniline do not reveal distinct chromosomal patterns at the light microscopic 
level. These cytological methods are not very reliable. The use of high resolution confocal laser scanning microscopy may allow reliable estimates of chromosome numbers of microscopic methods.

Electron microscopic analysis of yeast chromosomes by serial sectioning was performed with Schizosaccharomyces pombe (Erard \& Barker 1985). Analysis of synaptonemal complexes by serial sectioning (see Zickler et al. 1984) has been applied to some yeasts (Moens \& Rapport 1971; Zickler \& Olsen 1975). However, these electron microscopic methods are very time consuming.

Separation of chromosomal DNAs by pulsedfield gel electrophoresis is a distinct improvement (Schwartz \& Cantor 1984). These authors used perpendicularly oriented, non-uniform, and alternately pulsed electric fields for the electrophoretic separation of mitochondrial and chromosomal DNA, and $2 \mu \mathrm{m}$ plasmids of Saccharomyces cerevisiae. Moreover, hybridization with genetic markers for each of the genetically characterized linkage groups revealed a consistent correlation, despite the fact that only eleven bands could be separated. Slightly later, Carle \& Olson (1985) published similar results using orthogonal-field-alternation gel electrophoresis (OFAGE) and hybridization with chromosome-specific bands.

Chromosomal DNA molecules elongate and stretch parallel to the electric field. This principle is used in pulsed-field electrophoresis to force the DNA molecules to reorient due to periodic changes of the electric field. This results in so-called reptation of the DNA molecules through the pores of the gels. Important parameters influencing the separation of chromosomal DNA are pulse time, field strength, agarose concentration of the gel, and duration of electrophoresis. Short pulse times applied at a high field strength result in good separation of relatively small chromosomal DNAs, whereas long pulse times applied at a low field strength result in the separation of relatively large chromosomal DNAs.

During the last eight years considerable progress has been made in the devices used for pulsed-field electrophoresis. The double inhomogeneous electric field used in OFAGE (Carle \& Olson 1984, 1985 ) results in a strongly distorted separation of chromosomal DNAs, making the comparison of different lanes in a single gel difficult. A considerable improvement was the development of the CHEF system. Here a homogeneous electric field is applied using 24 electrodes which are arranged hexagonally (Chu 1989). Separation of chromosomal DNAs results in straight lanes allowing easy comparison of different strains. Application of size standards such as the chromosomal DNAs of Saccharomyces cerevisiae and Schizosaccharomyces pombe makes it possible to get rough estimates of genome sizes. Other systems providing straight lanes, but using other technical principles, are transverse alternating-field electrophoresis (TAFE), field-inversed gel electrophoresis (FIGE), rotating-gel electrophoresis (RGE), and ROTHAPHOR in which the electrodes periodically rotate. At present, it is possible to separate chromosomal DNAs of up to ca. $6 \mathrm{Mb}$ (Gunderson \& Chu 1991), and even $10 \mathrm{Mb}$ has been reported (Zhang et al. 1991). Pulsed-field techniques are useful for the isolation of plasmids, chromosomal and linear mitochondrial DNA (H. Fukuhara \& F. Sor, pers. comm.), as well as for the analysis of patterns of chromosomal DNA and chromosomal rearrangements, gene assessment, estimation of genome sizes, and molecular biotyping.

The number and size of chromosomes are to be considered as a character set of potential use in systematics. However, many species have rather variable karyotypes, which can be of use for fingerprinting of strains, but not necessarily the species themselves. Dynamics of chromosomal rearrangements may provide clues to the understanding of speciation processes.

\section{The use of pulsed-field techniques in the systematics of yeasts: some examples and limitations}

During the last few years, several studies have been published on the karyotypes of a variety of yeasts (e.g., de Jonge et al. 1986; Johnston et al. 1988).

Saccharomyces cerevisiae is among the best studied species (de Jonge et al. 1986; Johnston \& Mortimer 1986; Bakalinsky \& Snow 1990; Vezinhet et al. 
1990; Bidenne et al. 1992; van der Westhuizen \& Pretorius 1992). Fifteen of the sixteen genetically characterized chromosomes have been resolved. Considerable chromosomal length polymorphisms have been observed and, some chromosomes migrate as doublets due to their equal size. Yet, among species of Saccharomyces, Vaughan-Martini et al. (1993, this volume) observed a remarkable correlation between either the presence of similar karyotypes and high DNA similarities, or dissimilar karyotypes and low to medium DNA similarities.

Three chromosomal DNAs have been observed in Schizosaccharomyces pombe (Smith et al. 1986; Turmel \& Lalande 1988). Estimates of their size vary from 3000 to 3500,4600 to 6000 and 5700 to $9000 \mathrm{~kb}$, respectively (Smith et al. 1986; Vollrath \& Davies 1987; Fan et al. 1988).

Medically important Candida species have been extensively studied (Asakura et al. 1991; Iwaguchi et al. 1990; Mahrous et al. 1990; Rustchenko-Bulgac 1991; Snell \& Wilkins 1986; Suzuki et al. 1988). Chromosomal length polymorphisms have been observed in numerous species, and Rustchenko-Bulgac (1991) considers this phenomenon to be an important mechanism for increasing genetic variability of apomictic species. This hypothesis is supported by the observed correlation between chromosomal rearrangements and the occurrence of phenotypes that possibly are of evolutionary advantage (McEachern \& Hicks 1991; Wickes et al. 1991).

Other genera studied include Pichia (Miller et al.
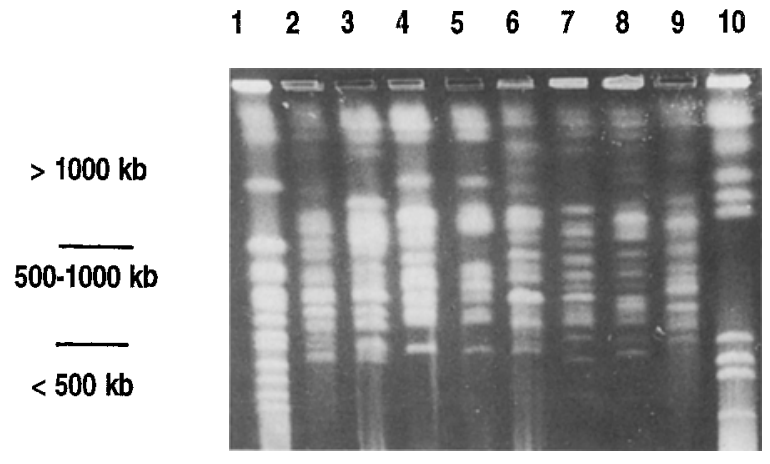

Fig. 1. Karyotypes of Hortaea werneckii. Electrophoretic conditions: CHEF, $24 \mathrm{~h}$ with pulse time ramping from 50 to $100 \mathrm{sec}$, followed by $24 \mathrm{~h}$ with pulse time ramping from 100 to $300 \mathrm{sec}$, $120 \mathrm{~V}, 14^{\circ} \mathrm{C}, 1 \%$ agarose, $0.5 \times \mathrm{TBE}$. Lane 1 Saccharomyces cerevisiae X 3402-15C; lanes 2 to 9 Hortaea werneckii: lane 2 CBS 410.51, from air, Japan; lane 3 CBS 107.67, from man, Portugal; lane 4 CBS 707.76, from sooty mold, Sri Lanka; lane 5 CBS 359.66, from man, Surinam; lane 6 CBS 111.31, from man, Brazil; lane 7 CBS 115.90, from kidney of Bufo granulosus, Brazil; lane 8 CBS 122.32, origin unknown; lane 9 CBS 116.90, from infected eye of Cantharus cantharus; lane 10 Malassezia furfur, type of Pityrosporum ovale, from man.

1989), Myxozyma and Lipomyces (Cottrell \& Kock 1990). Several species are characterized by constant numbers of chromosomal DNAs, but length polymorphisms do occur as well.

Kluyveromyces marxianus and K. lactis show different karyotypes (Steensma et al. 1988; Sor \& Fukuhara 1989), correlating well with restriction patterns of mtDNA (Sor \& Fukuhara 1989) and lack of gene exchange (Steensma et al. 1988). Diploid and

Table 1. Number and estimated sizes of chromosomal DNAs, and estimates of total genome size of Hortaea werneckii.

\begin{tabular}{llll}
\hline Strains & Number of chromosomal DNAs & Size of chromosomal DNAs (kb) & Total genome size (Mb) \\
\hline CBS 122.32 & $16-18$ & $510-2060(-2290)$ & $19.3-22.7$ \\
CBS 111.31 & $16-18$ & $540-2330$ & $19.8-21.7$ \\
CBS 410.51 & $17-18$ & $525-2460$ & $19.7-22.3$ \\
CBS 126.35 & 16 & $530-1905$ & 18.4 \\
CBS 707.61 & $17-18$ & $500-2105$ & $18.1-19.6$ \\
CBS 107.67 & 16 & $500-2290$ & $18.8-19.1$ \\
CBS 115.90 & $15-17$ & $305-2330$ & $18.2-18.4$ \\
CBS 705.76 & $14-15$ & $540-2130$ & $16.6-17.2$ \\
CBS 116.90 & 14 & $560-2330$ & $16.6-16.9$ \\
CBS 706.76 & 12 & $530-2130$ & $14.7-15.0$ \\
CBS 359.66 & 12 & $550-2290$ & $14.1-14.6$ \\
CBS 708.76 & 12 & $550-2130$ & $13.2-13.8$ \\
\hline
\end{tabular}


$\begin{array}{lllllllllll}12345678 & 9 & 1011 & 121314151617\end{array}$
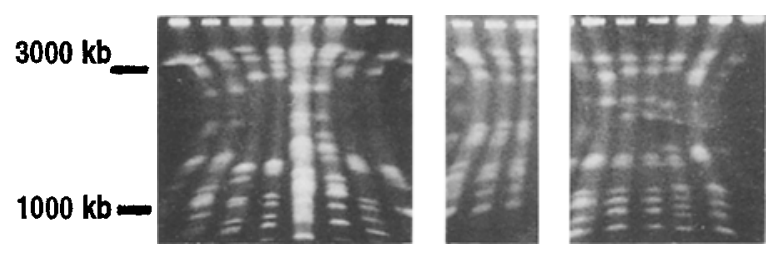

Fig. 2. Karyotypes of Filobasidiella neoformans varieties neoformans and bacillispora. Electrophoretic conditions: OFAGE, $48 \mathrm{~h}$ with pulse time $300 \mathrm{sec}$, followed by $24 \mathrm{~h}$ with pulse time $210 \mathrm{sec}, 120 \mathrm{~V}, 16^{\circ} \mathrm{C}, 0.9 \%$ agarose, $0.5 \times \mathrm{TBE}$. Lane $1 \mathrm{CBS} 132$, var. neoformans, from fermenting fruit juice; lane $2 \mathrm{CBS} 950$, var. neoformans, from tumour; lane 3 CBS 7229, var. bacillispora, from meningitis, China; lane 4 CBS 1934, var. bacillispora, from bovine mastitis; lane 5 CBS 464, var. neoformans, France; lane 6 CBS 1584, var. neoformans, origin unknown; lane 7 CBS 6290 , var. bacillispora, from man; lane 8 CBS 919, var. bacillispora, from lesion of meningo-encephalitis, USA; lane 9 RV 64610, var. neoformans, Rwanda; lane 10 RV 64612, var. neoformans, Rwan$\mathrm{da}$; lane $11 \mathrm{RV} 59369$, var. neoformans, from droppings of parakeet, Belgium; lane 12, var. neoformans, CBS 1009, from man; lane 13 CBS 6886, var. neoformans, from pigeon droppings; lane 14 CBS 6885, var. neoformans, from human bone lesion; lane 15 CBS 6901, var. neoformans, origin unknown; lane 16 CBS 1144 , var. neoformans, from spinal fluid; lane 17 CBS 996, var. neoformans, from blastomycosis.

aneuploid strains could be identified (Steensma et al. 1988).

The monotypic black yeastlike genus Hortaea, with $H$. werneckii as the sole species (de Hoog 1993, this volume), shows considerable variation in restriction patterns of the mtDNA (AWAM de Cock, unpublished results). All strains investigated also show a different karyotype (Fig. 1). The number of bands varies from twelve to eighteen, ranging in size between 305 and $2400 \mathrm{~kb}$ (Table 1). Estimates of genome sizes of the different strains vary from 13 to $23 \mathrm{Mb}$. Restriction groups 1 and 5 contain only species with large genomes, groups 2, 3 and 6 have low to intermediate genome sizes, whereas group 4 is heterogeneous.

Basidiomycetous yeasts have been studied relatively little. We investigated karyotypes of several ballistoconidium-forming yeastlike fungi belonging to the Tremellales and Tilletiales, and the medical yeasts Filobasidiella neoformans and Malassezia species.

Itersonilia is a monotypic genus belonging to the Tremellales, which forms di- and monokaryotic hy- phae and a monokaryotic yeast phase (Boekhout 1991a). Somatic hybridizations and DNA-binding studies revealed the presence of only one species (Boekhout et al. 1991a). The karyotype comprises ten to twelve bands which are all strain-specific. The transition from yeast cells to monokaryotic hyphae is associated with slight changes of the karyotypes comparable to those observed after colonytype switching in Candida albicans (Suzuki et al. 1989).

Tilletiopsis is a ballistoconidium-forming hyphomycete belonging to the Tilletiales, and currently comprises six species (Boekhout 1991b). The electrophoretic karyotypes coincide to a certain extent with other phenetic criteria for species delimitation.

Tilletiopsis fulvescens has seventeen to nineteen bands (Boekhout et al. 1991b), and shows two distinct banding patterns. North American isolates have karyotypes different from those of Japan.

Tilletiopsis minor reveals ten to fifteen bands, with a clustering that differs from that in the other species (Boekhout et al. 1991b). However, strain CBS 604.83 deviates considerably and this correlates with deviating isoenzyme patterns (Yamazaki et al. 1985).

Tilletiopsis washingtonensis, T. cremea and T. lilacina represent one and the same species (Boekhout 1991b). Twelve to twenty bands occur, and three more or less distinct patterns of banding do occur (Boekhout et al. 1991b). Strains of T. pallescens isolated from other fungi, and used as hyperparasites in powdery mildew control programs, show similar karyotypes.

The karyotypes of Entyloma calendulae show 1216 bands, most of them larger than $1000 \mathrm{~kb}$. The anamorph of Melanotaenium endogenum has a very different pattern showing 11 bands (Boekhout et al. 1991b). Karyotyping may serve as an additional criterion in species distinction, but the presence of chromosomal length polymorphisms hampers a straightforward interpretation.

Ninety strains of both varieties of Filobasidiella neoformans from the CBS and the Prins Leopold Institute for Tropical Medicine in Antwerp, Belgium were investigated by OFAGE (M. Renting, unpubl. results). Differentiation of the varieties neoformans and bacillispora was performed using D- 
proline assimilation and colour reaction on canavanine-glycine-brominethymolblue agar (CGB). In both varieties a considerable variation of the karyotypes was observed (Fig. 2). The number of bands ranged from seven to fourteen. Two types of banding were prevalent: 1 ) showing a more or less continuous series of bands ranging from ca. 500 to $3000 \mathrm{~kb}$, and 2) two clusters of bands (one ranging from ca. 500 to $2000 \mathrm{~kb}$, and one of around $3000 \mathrm{~kb}$ ). However, these two patterns seem to intergrade to a large extent. Both types occurred in both varieties, but the majority of strains of var. $b a$ cillispora had the second discontinuous type. Contrary to the results of Polacheck \& Lebens (1989), no obvious correlation was found with serotypes, nor with geography or habitat. Some strains, however, showed similar banding patterns, e.g., RV 46129 and RV 46119, both originating from India; RV 55447 of unknown origin and RV 58146 from wood in Kinshasa, Zaire; RV 66025 from Europe, CBS 1009 from man, CBS 2771 from spinal fluid, and CBS 6961 from man, USA (all $F$. neoformans var. neoformans); CBS 6993 from California (USA) and CBS 6994 from New Jersey (USA), both from clinical isolates; and RV 66095 from Brasil and RV 54130 from China (all $F$. neoformans var. bacillispo$\mathrm{ra}$ ). Our results confirm the prediction of Perfect et al. (1989), who expected considerable polymorphisms if many strains of $F$. neoformans were studied.

Malassezia species are lipophilic and propagate with monopolar percurrent or sympodial budding. Malassezia furfur is an obligate saprophyte or opportunistic human pathogen (Guého \& Meyer 1989) and has also been isolated from neonates (Ahtonen et al. 1990; Dankner et al. 1987; Guého et al. 1987a; Richet et al. 1989; Surmont et al. 1989). Malassezia pachydermatis is usually associated with otitis externa of dogs. However, this species has also been reported to be associated with systemic infections in humans (Guého et al. 1987a, b; Guého \& Meyer 1989), and has been isolated from neonates (Larocco et al. 1988; Mickelsen et al. 1988). The recently described third species, Malassezia sympodialis, has been isolated from the auditory tract of a healthy person, as well as from tinea capitis from an AIDS patient (Simmons \& Guého 1990). We inves- tigated strains from the CBS Yeast Division, and from the Departments of Neonatology and Dermatology of the Academic Hospital of the University of Leiden, The Netherlands.

All isolates of Malassezia pachydermatis studied show similar karyotypes that consist of five bands (Boekhout \& Bosboom 1991). Chromosomal length polymorphism was observed to occur in the lowermost band of $680-910 \mathrm{~kb}$. Strains of Malassezia furfur exhibit four different karyotypes. Most strains have seven chromosomal DNA bands (Boekhout \& Bosboom 1991). Among the CBS strains, the next to largest band shows length polymorphisms, whereas the hospital strains showed identical patterns. The second type has the smallest four bands in common with the first type, but six additional and different bands occur. The type strain of Pityrosporum ovale possesses this karyotype (Fig. 1). The third and fourth types, with eight and seven chromosomes respectively, completely differ from the other types. The fourth type includes the type strain of $M$. sympodialis.

Malassezia species show remarkably stable karyotypes. It seems desirable to extend our studies and to include DNA similarity studies among and between the four groups of $M$. furfur (including $M$. sympodialis) showing different types of chromosomal DNA banding. Malassezia furfur seems to be a good model for studying anamorphic genome evolution in basidiomycetes.

\section{Concluding remarks}

Electrophoretic karyotyping is a useful tool for analyzing the chromosomal structure of yeasts. Some species show remarkably stable karyotypes (Boekhout \& Bosboom 1991; Vaughan Martini et al.1993). The occurrence of chromosomal length polymorphisms may allow fingerprinting of strains which may benefit epidemiology and the establishment of proprietary rights. In many cases, a taxonomic interpretation is hampered by the occurrence of chromosomal length polymorphisms, chromosomal rearrangements, aneuploidy and comigrating bands. Moreover, large chromosomal DNAs do not always show a linear relationship between molecular size 
and distance migrated. This is due to mobility inversion, DNA entrapment, and band spreading (Gunderson \& Chu 1991). If the karyotype comprises small and/or medium-sized bands, genome sizes can be estimated. The usefulness of karyotyping in estimating genome sizes of yeasts and fungi may increase by subsequent application of macrorestriction analysis (Fan et al. 1988), densitometry (Mahrous et al. 1990), hybridization with band-specific probes, and an increase in the separation of largesized bands. It is expected that the integration of karyotyping, genetics, systematics and chromosome-based DNA hybridization experiments (Török \& King 1992) will contribute to a better understanding of mechanisms of chromosomal diversification, and to the understanding of speciation processes.

\section{References}

Ahtonen P, Lehtonen O-P, Kero P, Tunnela E \& Havu V (1990) Malassezia furfur colonization of neonates in an intensive care unit. Mycoses 33: 543-547

Asakura K, Iwaguchi S-I, Homma M, Sukai T, Higashide K \& Tanaka K (1991) Electrophoretic karyotypes of clinically isolated yeasts of Candida albicans and C. glabrata. J. Gen. Microbiol. 137: 2531-2538

Bakalinsky AT \& Snow R (1990) The chromosomal constitution of wine strains of Saccharomyces cerevisiae. Yeast 6: 367-382

Bidenne C, Blondin B, Dequin S \& Vezinhet F (1992) Analysis of the chromosomal DNA polymorphism of wine strains of Saccharomyces cerevisiae. Curr. Genet. 22: 1-7

Boekhout T (1991a) Systematics of Itersonilia: a comparative phenetic study. Mycol. Res. 95: 135-146

Boekhout T (1991b) A revision of ballistoconidia-forming yeasts and fungi. Stud. Mycol. 33: 1-191

Boekhout T \& Bosboom R (1991) Karyotyping of basidiomycetous yeasts. In: Macromolecular identification and classification of organisms, P-30. Antwerp

Bockhout T \& Jille T (1991) Mitosis and DNA contents in yeast cells of Itersonilia perplexans. Syst. Appl. Microbiol. 14: 117123

Boekhout T, Poot G, Hackman P \& Steensma HY (1991a) Genomic characteristics of strains of Itersonilia: taxonomic consequences and life cycle. Can. J. Microbiol. 37: 188-194

Boekhout T, Gool J van, Boogert H van den \& Jille T (1991b) Karyotyping and $\mathrm{G}+\mathrm{C}$ composition as taxonomic criteria applied to the systematics of Tilletiopsis and related taxa. Mycol. Res. 96: 331-342

Carle GF \& Olson MV (1984) Separation of chromosomal DNA molecules from yeast by orthogonal-field-alternation gel electrophoresis. Nucl. Acids. Res. 12: 5647-5664

Carle GF \& Olson MV (1985) An electrophoretic karyotype for yeasts. Proc. Nat. Acad. Sc. USA 82: 3756-3760

Chu G (1989) Pulsed field electrophoresis in contour clamped homogeneous electric field for the resolution of DNA by size or topology. Electrophoresis 10: 290-295

Cottrell M \& Kock JLF (1990) An electrophoretic karyotype comparison of the yeast genera Dipodascopsis Batra et Miller, Lipomyces Lodder et Kreger-van Rij, Myxozyma van der Walt et von Arx. Syst. Appl. Microbiol. 13: 136-141

Dankner WM, Spector SA, Fierer J \& Davis CE (1987) Malassezia fungemia in neonates and adults: complication of hyperalimentation. Rev. Infect. Dis. 9: 743-753

Erard M \& Barker DG (1985) Electron microscopic studies of condensed mitotic chromosomes in the fission yeast Schizosaccharomyces pombe. Biol. Cell. 55: 27-34

Fan J-B, Chikashige Y, Smith CL, Niwa O, Yanagida M \& Cantor CR (1988) Construction of a Not I restriction map of the fission yeast Schizosaccharomyces pombe genome. Nucl. Acids Res. 17: 2801-2818

Fischer P, Binder M \& Wintersberger U (1975) A study of the chromosomes of the yeast Schizosaccharomyces pombe by light and electron microscopy. Exp. Cell. Res. 96: 15-22

Galeotti CL \& Williams KL (1978) Giemsa staining of mitotic chromosomes in Kluyveromyces lactis and Saccharomyces cerevisiae. J. Gen. Microbiol. 104: 337-341

Guého E \& Meyer SA (1989) A reevaluation of the genus Malassezia by means of genome comparison. Antonie van Leeuwenhoek 55: 245-251

Guého E, Simmons RB \& Ahearn DG (1987a) Malassezia spp. et infections systemiques. Bull. Soc. Fr. Mycol. Med. 16: 329-332

Guého E, Simmons RB, Pruitt WR, Meyer SA \& Ahearn DG (1987b) Association of Malassezia pachydermatis with systemic infections of humans. J Clin Microbiol 25: 1789-1790

Gunderson K \& Chu G (1991) Pulsed-field electrophoresis of megabase-sized DNA. Mol. Cell. Biol. 11: 3348-3354

Hoog GS de (1993) Evolution of black yeasts: possible adaptation to the human host (this volume)

Iwaguchi S-I, Homma M \& Tanaka K (1990) Variation in the electrophoretic karyotype analysed by the assignment of DNA probes in Candida albicans. J. Gen. Microbiol. 136: 2433-2442

Johnston JR, Contopoulou CR \& Mortimer RK (1988) Karyotyping of yeast strains of several genera by field inversion gel electrophoresis. Yeast 4: 191-198

Johnston JR \& Mortimer RK (1986) Electrophoretic karyotyping of laboratory and commercial strains of Saccharomyces and other yeasts. Int. J. Syst. Bact. 36: 569-572

Jonge P de, Jongh FCM de, Meijers R, Steensma HY \& Scheffers WA (1986) Orthogonal-field-alternation gel electrophoresis banding patterns from yeasts. Yeast 2: 193-204

Larocco M, Dorenbaum A, Robinson A \& Pickering LK (1988) Recovery of Malassezia pachydermatis from eight infants in a neonatal intensive care nursery: clinical and laboratory features. Pediatr. Infect. Dis. J. 7: 389-401 
Mahrous M, Lott TJ, Meyer SA, Sawant AD \& Ahearn DG (1990) Electrophoretic karyotyping of typical and atypical Candida albicans. J. Clin. Microbiol. 28: 876-881

McEachern MJ \& Hicks JB (1991) Dosage of smallest chromosome effects both the yeast-hyphal transition and the whiteopaque transition of Candida albicans WO-I. J. Bact. 173: 7436-7442

Mickelsen PA, Viano-Paulson MC, Stevens DA \& Diaz PS (1988) Clinical and microbiological features of infection with Malassezia pachydermatis in high-risk infants. J. Infect. Dis. 157: 1163-1168

Miller M, Kock JLF, Pretorius GHJ \& Coetzee DJ (1989) The value of orthogonal-field-alternation gel electrophoresis and other criteria in the taxonomy of the genus Pichia Hansen emend. Kurtzman. Syst. Appl. Microbiol. 12: 191-202

Moens PB \& Rapport E (1971) Spindles, spindle-plaques, and meiosis in the yeast Saccharomyces cerevisiae (Hansen). J. Cell. Biol. 50: 344-361

Perfect JR, Magee BB \& Magee MT (1989) Separation of chromosomes of Cryptococcus neoformans by pulsed field gel electrophoresis. Infect. Immun. 57: 2624-2627

Polacheck I \& Lebens GA (1989) Electrophoretic karyotype of the pathogenic yeast Cryptococcus neoformans. J. Gen. Microbiol. 135: 65-71

Richet HM, McNeil MM, Edwards MC \& Jarvis WR (1989) Cluster of Malassezia furfur pulmonary infections in infants in a neonatal intensive-care unit. J. Clin. Microbiol. 27: 1197-1200

Robinow CF (1961) Mitosis in the yeast Lipomyces lipofer. J. Biophys. Biochem. Cytol. 9: 879-892

Rustchenko-Bulgac EP (1991) Variations of Candida albicans electrophoretic karyotypes. J. Bact. 173: 6585-6596

Schwartz DC \& Cantor CR (1984) Separation of yeast chromosome-sized DNA's by pulsed field gradient gel electrophoresis. Cell 37: 67-75

Simmons RB \& Guého E (1990) A new species of Malassezia. Mycol. Res. 94: 1146-1149

Smith CL, Warburton PE, Gaal A \& Cantor CR (1986) Analysis of genome organization and rearrangements by pulsed field gradient gel electrophoresis. Genet. Engin. 8: 45-70

Snell RG \& Wilkins RJ (1986) Separation of chromosomal DNA molecules from C. albicans by pulsed field gel electrophoresis. Nucl. Acids. Res. 14: 4401-4406

Sor F \& Fukuhara H (1989) Analysis of chromosomal DNA patterns of the genus Kluyveromyces. Yeast 5:1-10

Steensma HY, Jongh FCM de \& Linnekamp M (1988) The use of electrophoretic karyotypes in the classification of yeasts: Kluyveromyces marxianus and K. lactis. Curr. Genet. 14: 311317

Surmont I, Gavilanes A, Vandepitte J, Devlieger H \& Eggermont E (1989) Malassezia furfur fungaemia in infants receiving intravenous lipid emulsions. A rarity or just underestimated. Eur. J. Pediatr. 148: 435-438
Suzuki T, Kobayashi I, Mizuguchi I, Banno I \& Tanaka K (1988) Electrophoretic karyotyping in medically important Candida species. J. Gen. Appl. Microbiol. 34: 409-416

Suzuki T, Kobayashi I, Kanbe T \& Tanaka K (1989) High frequency variation of colony morphology and chromosome reorganization in the pathogenic yeast Candida albicans. J. Gen. Microbiol. 135: 425-434

Tolmsoff WJ (1983) Heteroploidy as a mechanism of variability among fungi. Ann. Rev. Phytopath. 21: 317-340

Török T \& King AD (1992) Use of electrophoretic karyotyping and DNA-DNA hybridization probes for the identification of yeasts. Abstr. $8^{\text {th }}$ Int. Symp. Yeasts (p. 48) Atlanta

Turmel C \& Lalande M (1988) Resolution of Schizosaccharomyces pombe chromosomes by field inversion gel electrophoresis. Nucl. Acids. Res. 16: 4727

Vaughan-Martini A, Martini A \& Cardinale G (1993) Electrophoretic karyotyping as a taxonomic tool in the genus Saccharomyces. (this volume)

Vezinhet F, Blondin B \& Hallet J (1990) Chromosomal DNA patterns and mitochondrial DNA polymorphism as tools for identification of enological strains of Saccharomyces cerevisiae. Appl. Microbiol. Biotechnol. 32: 568-571

Vollrath D \& Davis RW (1987) Resolution of DNA molecules greater than 5 megabases by contour-clamped homogeneous electric fields. Nucl. Acids. Res. 15: 7865-7876

Walt JP van der \& Pitout MJ (1969) Ploidy differences in Sporobolomyces salmonicolor and Candida albicans. Antonie van Leeuwenhoek 35: 227-231

Westhuizen TJ van der \& Pretorius IS (1992) The value of electrophoretic fingerprinting and karyotyping in wine yeast breeding programmes. Antonie van Leeuwenhoek 61: 249257

Wickes BL, Golin JE \& Kwon-Chung KJ (1991) Chromosomal rearrangement in Candida stellatoidea results in a positive effect on phenotype. Infect Immun 59: 1762-1771

Yamazaki M, Goto S \& Komagata K (1985) Taxonomic studies of the genus Tilletiopsis on physiological properties and electrophoretic comparison of enzymes. Trans. Mycol. Soc. Japan 26: 13-22

Zhang TY, Smith CL \& Cantor CR (1991) Secondary pulsed field gel electrophoresis: a new method for faster separation of larger DNA molecules. Nucl. Acids. Res. 19: 1291-1296

Zickler D \& Olson LW (1975) The synaptonemal complex and the spindle plaque during meiosis in yeast. Chromosoma 50 : 1-23

Zickler D, Leblon G, Haedens V, Collard A \& Thuriaux (1984) Linkage group-chromosome correlations in Sordaria macrospora: chromosome identification by three dimensional reconstruction of their synaptonemal complex. Curr. Genet. 8: 57-67 